\title{
Prevalência de tuberculose, brucelose e infecções víricas em bovinos leiteiros do município de Passo Fundo, RS
}

\author{
Prevalence of tuberculosis, brucelosis and viral infections in dairy cattle \\ from the county of PassoFundo, RS, Brazil
}

\section{Rosangela Poletto ${ }^{1}$ Luiz Carlos Kreutz ${ }^{2}$ João Carlos Gonzales ${ }^{3}$ Leonardo José Gil Barcellos ${ }^{4}$}

\begin{abstract}
Dois mil cento e dezenove bovinos adultos pertencentes a 156 propriedades leiteiras distribuídas em 22 localizadas do município de Passo Fundo foram testados para tuberculose bovina (TB) e brucelose bovina $(B B) . \quad A$ prevalência de anticorpos contra o vírus da diarréia viral bovina (BVDV), vírus da leucose enzoótica bovina (BLV) e herpesvírus bovino tipo 1 (BHV-1) foi estimada por amostragem aleatória em 28 dessas propriedades. Para tanto, considerou-se prevalência acima de $30 \%$ para essas infecções e intervalo de confiança de 90\%, e sorteou-se 204 amostras de soro sangüíneo. Entre os 2.119 animais testados, 32 (1,51\%) foram positivos para TB e 26 (1,22\%) foram positivos para $B B$. Os exames sorológicos dos animais pertencentes às 28 propriedades indicaram animais positivos para $\mathrm{BHV}-1$, BVDV e BLV em 22 (92,85\%), $19(67,85 \%)$ e $17(60,71 \%)$ propriedades, respectivamente; $11(39,28 \%)$ propriedades apresentaram animais soropositivos tanto para $B H V-1, B V D V$ e BLV; em 1 (3,57\%) propriedade apenas todos os animais eram soronegativos para essas infecções.

Palavras-chave: doenças de bovinos, epidemiologia, tuberculose bovina (TB), brucelose bovina $(B B)$, vírus da diarréia viral bovina (BVD), vírus da leucose enzoótica bovina (LEB) e herpesvírus bovino (BHV-1).
\end{abstract}

\section{ABSTRACT}

Two thousand one hundred and nineteen bovines belonging to 156 dairy herds distributed among 22 counties in Passo Fundo, RS, were tested for bovine tuberculosis (BT) and bovine brucellosis (BB). The prevalence of antibodies to bovine viral diarrhea virus (BVDV), enzootic bovine leukemia virus (BLV) and bovine herpesvirus (BHV-1) was estimated by random sampling in 28 properties; considering a prevalence of infection of at least $30 \%$ and a confidence interval of $90 \%$, 204 serum samples were tested. Among de 2119 bovines, 32 (1.51\%) were positive for $T B$ and $26(1.22 \%)$ were positive for $B B$. The serological tests of the animals belonging to the 28 herds indicated the presence of antibodies to BHV-1, BVDV and BLV in 22 (92.35\%), 19 (67.35\%) and 17 (60.71\%) herds, respectively; 11 (39.28\%) properties had animals positive to $B H V-1, B V D V$ and $B L V$, and in only $1(3.57 \%)$ herd all animals tested were negative to these infections.

Key words: cattle diseases, epidemiology, bovine tuberculosis $(T B)$, bovine brucellosis (BB), bovine herpesvirus $(B H V-1)$, enzootic bovine leukemia virus (BLV), bovine viral diarrhea virus (BVDV).

O aumento da concentração de bovinos por propriedade, a introdução de material genético proveniente de outros países e a alteração do manejo sanitário e reprodutivo, facilitaram a disseminação de diversos microorganismos patogênicos de grande importância sanitária e econômica para a bovinocultura leiteira. A investigação sobre as infecções mais comuns de bovinos leiteiros indicou que o herpevírus bovino (BHV-1), o vírus da diarréia viral bovina (BVDV), e o vírus da leucose enzoótica bovina (BLV),

\footnotetext{
${ }^{1}$ Aluno do Curso de Medicina Veterinária, Bolsista PIBIC/CNPq.

${ }^{2}$ Médico Veterinário, MSc, PhD, Laboratório de Virologia e Imunologia, Hospital Veterinário, Faculdade de Agronomia e Medicina Veterinária (FAMV), Universidade de Passo Fundo (UPF), Campus I, Bairro São José, 99001-970, Passo Fundo, RS. E-mail: 1ckreutz@upf.tche.br. Autor para correspondência. Pesquisa com apoio da FAPERGS (98/1835-3).

${ }^{3}$ Médico Veterinário, MS, Doutor, Laboratório de Doenças Parasitárias, Hospital Veterinário, FAMV, UPF.

${ }^{4}$ Médico Veterinário, MS, Doutor, Laboratório de Ictiopatologia, Hospital Veterinário, FAMV, UPF.
} 
têm alta prevalência nos bovinos do Sul do Brasil (FLORES et al., 1992; LOVATO, 1998; ROEHE et al., 1988a, 1998b). A tuberculose bovina (TB) e a brucelose bovina (BB) têm baixa prevalência em função da exigência de testes periódicos impostos pela empresas beneficiadoras de leite.

A TB e BB, além da importância em saúde pública, interferem na capacidade plena de produção causando reduções de até $25 \%$ na produtividade animal (COSTA, 2001; RIET-CORREA \& GARCIA, 2001). As infecções por BHV-1 e BVDV manifestam-se principalmente por transtornos reprodutivos como repetições de cio, mortalidade embrionária e fetal, mumificações e abortos (HALFEN \& VIDOR, 2001; ROEHE \& WEIBLEN, 2000; SCHUCH, 2001). A infecção pelo BLV tem maior importância na forma tumoral em animais mais velhos, interferindo com diversas funções fisiológicas (BRAGA \& VAN DER LAAN, 2001).

O presente trabalho objetivou elucidar os aspectos epidemiológicos da TB, BB, e das infecções pelo BHV-1, BVDV e BLV no rebanho leiteiro do município de Passo Fundo, e fornecer subsídios para futuras investigações, visando melhorar a produtividade através da sanidade animal.

Foram analisados 2.119 bovinos leiteiros das raças Holandesa e Jersey, com, no mínimo, 30 meses de idade, pertencentes a 156 propriedades de 22 localidades do município de Passo Fundo, Rio Grande do Sul. Todos os animais testados apresentavam-se clinicamente saudáveis e em produção no momento do teste para $\mathrm{TB}$ e da coleta das amostras de sangue. O diagnóstico da TB foi realizado pela inoculação de $0,1 \mathrm{ml}$ da Proteína Purificada Derivada (PPD ${ }^{a}$ ) na prega caudal dos animais, seguida de leitura com auxílio de um paquímetro 72 horas após a inoculação. A pesquisa de anticorpos contra a Brucella abortus foi feita utilizando-se a Técnica de Aglutinação Rápida em Placa com Antígeno Acidificado Tamponado (Card Test $\left.{ }^{a}\right)$ e, quando positivo, titulação pela Técnica de Soroaglutinação Rápida em Placa (SARPa), Soroaglutinação Lenta em Tubo e concomitante redução pelo Mercaptoetanol ${ }^{\mathrm{a}}$. A detecção de anticorpos contra BHV-1, BVDV e BLV foi realizada por meio de uma amostragem da população total; estimando-se uma prevalência de BHV-1, BVDV e BLV superior a $30 \%$ e, com um intervalo de confiança de $90 \%$ obteve-se 204 amostras de soro sangüíneo (Win Episcope 2.0 - BLAS et al., 2002; TOMA et al., 1996), distribuídas em 28 propriedades. Anticorpos contra BHV-1 e BVDV foram detectados pela técnica de soro-neutralização (BOTTON et al., 1998). O diagnóstico da infecção pelo BLV foi feita por imunodifusão em gel de ágar (IDGA ${ }^{\mathrm{a}}$ ) conforme descrito anteriormente (MILLER et al., 1981).

Os testes intradérmicos para diagnóstico da TB indicaram que $32(1,51 \%)$ dos animais testados apresentaram reações positivas, sendo que, destes, somente 1 animal não apresentava lesões condizentes com TB por ocasião do abate feito sob Inspeção Municipal (dados não mostrados). Os animais positivos pertenciam a $6(3,84 \%)$ propriedades, sendo que estas se localizavam em 4 localidades distintas. Anticorpos contra B. abortus foram detectados em $26(1,22 \%)$ bovinos, os quais se encontravam em $3(1,92 \%)$ propriedades.

Os exames sorológicos para BVDV, BHV-1 e BLV indicaram que, das 28 propriedades que tiveram seus animais testados, $19(67,85 \%)$ apresentaram animais soropositivos para BVDV, $22(92,85 \%)$ possuíam animais soropositivos para BHV-1 e 17 $(60,71 \%)$ possuíam pelo menos um animal soropositivo para BLV. Entre as 28 propriedades avaliadas, $11(39,28 \%)$ possuíam em comum, animais soropositivos para BHV-1, BVDV e BLV e, em apenas $1(3,57 \%)$ propriedade não foi possível detectar a presença de animais positivos para BHV-1, BVDV ou BLV (Tabela 1).

Dados epidemiológicos sobre a prevalência de TB e BB são escassos, o que dificulta o estudo sistemático do impacto econômico dessas enfermidades no rebanho bovino leiteiro, o qual oferece maior possibilidade de contaminação aos humanos, pelo contato e consumo de leite e seus derivados. Em relação à TB, no RS, ALMEIDA et al. (1997) estimaram uma prevalência de 1,33\%. Em São Paulo, observou-se uma prevalência de $15,64 \%$ (MELO et al., 1997), enquanto, no Rio de Janeiro, LILENBAUM et al. (1999), observaram uma taxa de infecção de 12,7\% em 1622 animais de 13 propriedades com história prévia de TB. A variação na prevalência da TB nas diferentes regiões pode estar relacionada a diversos fatores como fonte de aquisição de animais, manejo, clima e ao serviço de diagnóstico da tuberculose em cada propriedade. Na região estudada, é comum a compra de animais da região sul do RS e mesmo do Uruguai, sendo que estes foram identificados como fatores de risco para a introdução da TB e BLV (FLORES et al., 1992). Em relação à $\mathrm{BB}$, a inexistência de dados epidemiológicos divulgados em meios científicos dificulta fazer uma análise comparativa com outras regiões. Em função disso, torna-se difícil estabelecer o impacto dessas doenças na bovinocultura de leite e saúde pública. 
Tabela 1 - Prevalência de anticorpos contra o herpesvirus bovino (BHV-1), vírus da diarréia viral bovina (BVDV) e vírus da leucose enzoótica bovina (BLV) em 28 propriedades leiteira do Município de Passo Fundo, RS. O número de amostras de cada propriedade foi determinado estimando uma prevalência de pelo menos $30 \%$ de cada enfermidade e com intervalo de confiança de $90 \%$.

\begin{tabular}{|c|c|c|c|c|}
\hline Propriedade & $\mathrm{N}^{\circ}$ amostras testadas & $\begin{array}{c}\mathrm{N}^{\circ} \text { amostras positivas para } \\
\text { BHV-1 }\end{array}$ & $\begin{array}{c}\mathrm{N}^{\circ} \text { amostras positivas para } \\
\text { BVDV }\end{array}$ & $\begin{array}{c}\mathrm{N}^{\circ} \text { amostras positivas para } \\
\text { BLV }\end{array}$ \\
\hline 1 & 06 & 01 & 0 & 0 \\
\hline 2 & 06 & 04 & 02 & 02 \\
\hline 3 & 08 & 02 & 06 & 0 \\
\hline 4 & 08 & 04 & 03 & 0 \\
\hline 5 & 03 & 01 & 02 & 03 \\
\hline 6 & 08 & 02 & 0 & 03 \\
\hline 7 & 09 & 03 & 02 & 04 \\
\hline 8 & 07 & 03 & 03 & 01 \\
\hline 9 & 08 & 03 & 01 & 0 \\
\hline 10 & 07 & 02 & 0 & 03 \\
\hline 11 & 08 & 01 & 01 & 0 \\
\hline 12 & 07 & 05 & 06 & 0 \\
\hline 13 & 07 & 02 & 06 & 02 \\
\hline 14 & 08 & 02 & 0 & 01 \\
\hline 15 & 07 & 03 & 01 & 01 \\
\hline 16 & 07 & 05 & 02 & 04 \\
\hline 17 & 09 & 04 & 01 & 05 \\
\hline 18 & 06 & 02 & 0 & 01 \\
\hline 19 & 07 & 01 & 0 & 0 \\
\hline 20 & 07 & 03 & 02 & 0 \\
\hline 21 & 07 & 03 & 04 & 02 \\
\hline 22 & 08 & 01 & 05 & 0 \\
\hline 23 & 08 & 0 & 0 & 0 \\
\hline 24 & 08 & 02 & 07 & 04 \\
\hline 25 & 08 & 01 & 01 & 02 \\
\hline 26 & 07 & 02 & 0 & 0 \\
\hline 27 & 08 & 0 & 0 & 06 \\
\hline 28 & 07 & 05 & 05 & 04 \\
\hline TOTAL & 204 & 67 & 60 & 48 \\
\hline
\end{tabular}

Para a detecção de anticorpos contra BHV1, BVDV e BLV, o método de amostragem utilizada para obtenção das amostras de soro, foi efetuada utilizando Win Episcope 2.0 (BLAS et al., 2002) e preconizou-se uma prevalência de, pelo menos, $30 \%$ dessas infecções. Conforme resultados apresentados na tabela 1, observa-se que as infecções pelo BHV-1, BVDV e BLV encontram-se amplamente disseminadas nos rebanhos estudados, com prevalência de, pelo menos, $30 \%$ em cada rebanho. Estudos epidemiológicos anteriores abrangendo a região em questão, indicaram uma prevalência de $12 \%$ para IBR (LOVATO et al., 1995) e de 7,1\% para BLV, sendo que o BLV foi diagnosticado em $26,5 \%$ das propriedades na região estudada (MORAES et al., 1996). Visto que não houve aplicação de vacinas contra BHV-1 e BVDV anteriormente à coleta do sangue e que o método de amostragem preconizou uma prevalência mínima de $30 \%$ das enfermidades, pode-se concluir que o aumento significativo na prevalência dessas infecções nos últimos anos pode estar associado à falta de medidas profiláticas e ausência de diagnóstico, o que possibilitou a introdução de animais infectados e posterior contaminação dos rebanhos.

\section{FONTES DE AQUISIÇÃO}

a TECPAR - Instituto de Tecnologia do Paraná.

\section{AGRADECIMENTOS}

Os autores agradecem a colaboração do Médico Veterinário Ary Carneiro Gomide Jr. e do Zootecnista Anilson Miranda. Agradecimentos também à equipe do Setor de Virologia da Universidade Federal de Santa Maria, UFSM, onde foram realizados os exames de soroneutralização para IBR e BVD.

Ciência Rural, v. 34, n.2, mar-abr, 2004. 


\section{REFERÊNCIAS BIBLIOGRÁFICAS}

ALMEIDA, Z.A.; CHIMINAZZO, C. Ocorrência de tuberculose bovina em propriedades leiteiras nos municípios de Guaíba e Eldorado do Sul. In: CONGRESSO BRASILEIRO DE MEDICINA VETERINÁRIA, 22., CONGRESSO ESTADUAL DE MEDICINA VETERINÁRIA, 8., E CONGRESSO DE MEDICINA VETERINÁRIA DO CONE SUL, 2., 1997, Gramado,RS. Anais... Porto Alegre : SOVERGS, 1997. V.1, p.167.

BLAS, I. et al. Win Episcope 2.0, EPIDECON, Borland®

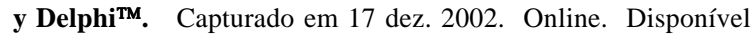
na internet: http://www.clive.ed.ac.ed/winepiscope/.

BRAGA, F.B.; VAN DE LAAN, C.W. Leucose enzoótica bovina. In: RIET-CORREA F. et al. (Ed.). Doenças de ruminantes e eqüinos. 2.ed. São Paulo : Varela, 2001. V.1, p.126-134.

BOTTON, S.A. et al. Antigenic characterization of brazilian bovine viral diarrhoea virus isolates by monoclonal antibodies and cross-neutralization. Braz J Med Biol Res, n. 31, p.1429-1438, 1998.

COSTA, M. Brucelose bovina e eqüina. In: RIET-CORREA F. et al. (Ed.). Doenças de ruminantes e eqüinos. 2.ed. São Paulo : Varela, 2001. V.1, p.187-197.

FLORES, E.F. et al. Anticorpos contra o vírus da Leucose Bovina (VLB) em soros de bovinos provenientes da República Oriental do Uruguai. A Hora Veterinária. n.68, p.5-8, 1992.

HALFEN, D.C. ; VIDOR, T. Infecções por herpesvírus bovino tipo 1 e herpesvírus bovino tipo 5. In: RIET-CORREA F. et al. (Ed.). Doenças de ruminantes e eqüinos. 2.ed. São Paulo : Varela, 2001. V.1, p.97-108.

LILENBAUM, W. et al. Evaluation of ELISA and PPD for the diagnosis of bovine tuberculosis in field trials in Brazil. $\mathbf{J}$ Res Vet Sci, n.66, p.191-195, 1999.

LOVATO, L.T. et al. Herpesvírus bovino tipo 1 (HVB-1): inquérito soro-epidemiológico no rebanho leiteiro do estado do Rio Grande do Sul, Brasil. Ciência Rural, v.25, n.3, p.425-430, 1995.

LOVATO, L.T. BHV-1-1 e BHV-1-5, isolamentos e sorologia no Rio Grande do Sul. In: I SIMPÓSIO INTERNACIONAL
SOBRE HERPESVÍRUS BOVINO (TIPO 1 E 5) E VÍRUS DA DIARRÉIA VIRAL BOVINA (BVBV), 1998, Santa Maria, RS. Anais... Santa Maria, RS, 1998. p.97-101.

MELO, H.E.L.; DANGELINO, L.J.; SCHLACH, M.U. Ocorrência de tuberculose bovina em vacas de rebanhos leiteiros do Estado de São Paulo. In: CONGRESSO BRASILEIRO DE MEDICINA VETERINÁRIA, 25., CONGRESSO ESTADUAL DE MEDICINA VETERINÁRIA, 12., CONGRESSO DE MEDICINA VETERINÁRIA DO CONE SUL, 2., 1997, Gramado, RS. Anais... Porto Alegre : SOVERGS, 1997. p.165.

MILLER, J.M.; SCHMERR, J.F.; VAN DER MAATEN, M.J. Comparison of four tests for the detection of antibodies to bovine leukemia virus. Am J Vet Res, n.42, p.5-8, 1981.

MORAES, M.P. et al. Levantamento sorológico da infecção pelo vírus da leucose bovina nos rebanhos leiteiros do estado do Rio Grande do Sul, Brasil. Ciência Rural, v.26, n.2, p.257-262, 1996.

RIET-CORREA, F.; GARCIA, M. Tuberculose. In: RIETCORREA F. et al. (Ed.). Doenças de ruminantes e eqüinos. 2.ed. São Paulo : Varela, 2001. V.1, p.351-362.

ROEHE, P.M. et al. A situação do vírus da Diarréia Viral Bovina no Brasil. In: SIMPÓSIO INTERNACIONAL SOBRE HERPESVÍRUS BOVINO (TIPO 1 E 5) E VÍRUS DA DIARRÉIA VIRAL BOVINA (BVBV), 1., 1998a, Santa Maria, RS. Anais... Santa Maria, RS, 1998a. p.39-48.

ROEHE, P.M. et al. A situação do BHV-1-1 e BHV-1-5 no Brasil. In: SIMPÓSIO INTERNACIONAL SOBRE HERPESVÍRUS BOVINO (TIPO 1 E 5) E VÍRUS DA DIARRÉIA VIRAL BOVINA (BVBV), 1., 1998b, Santa Maria, RS. Anais... Santa Maria, RS, 1998b. p.89-94.

ROEHE, P.M.; WEIBLEN, R. IBR e BVD: perguntas e respostas. A Hora Veterinária. Ano 20, n.116, p.69-73, 2000 .

SCHUCH, L.F.D. Diarréia viral bovina. In: RIET-CORREA F. et al. (Ed.). Doenças de ruminantes e eqüinos. 2.ed. São Paulo : Varela, 2001. V.1, p.65-72.

TOMA, B. et al. Applied veterinary epidemiology and the control of disease in populations. France : AEEMA, 1996. 536p. 